\title{
Akt2-Dependent Beneficial Effect of Galanin on Insulin-Induced Glucose Uptake in Adipocytes of Diabetic Rats
}

\author{
Zhenwen Zhang ${ }^{\mathrm{a}}$ Penghua Fang ${ }^{\mathrm{b}, \mathrm{c}}$ Lili Guo ${ }^{\mathrm{b}}$ Biao He $\mathrm{H}^{\mathrm{b}}$ Mingyi Shi ${ }^{\mathrm{b}}$ Yan Zhu ${ }^{\mathrm{a}}$ \\ Ping $\mathrm{Bo}^{\mathrm{a}, \mathrm{b}}$
}

aDepartment of Endocrinology, Clinical Medical College, 'ey Rresearch Institute of Gerontology, Medical College, Yangzhou University, Yangzhou, Jiangsu, 'Department of Physiology, School of Hanlin, Nanjing University of Chinese Medicine, Taizhou, Jiangsu, China

\author{
Key Words \\ AS160 • FoxO1・GSK-3 • GLUT4 • VAMP2
}

\begin{abstract}
Background/Aims: Glucose uptake occurs via the activation of an insulin-signaling cascade, resulting in the translocation of glucose transporter 4 (GLUT4) to the plasma membrane of adipocytes and myocytes. Recent research found that galanin could boost insulin-induced glucose uptake. This study aimed to explore whether activation of Akt2 mediates the beneficial effects of galanin on insulin-induced glucose uptake in the adipocytes of diabetic rats. Method: In this experiment, insulin, galanin and MK-2206, an Akt inhibitor, were injected individually or in combination into diabetic rats once a day for ten days. Then, glucose uptake and pAkt2 and its downstream proteins were examined in adipocytes. Results: Administration of galanin significantly enhanced insulin-induced 2-Deoxy-D-[$\left.{ }^{3} \mathrm{H}\right]$ glucose uptake; GLUT4 and vesicle-associated membrane protein 2 contents in plasma membranes; and pAkt2 ${ }^{\text {Thro } 308 /}$ Ser473 and Akt2 mRNA expression levels in adipocytes. In addition, Akt2 downstream proteins including phosphorylated AS160 were increased, but the levels of phosphorylated forkhead box $\mathrm{O} 1$ and glycogen synthase kinase-3 $\beta$ were reduced. Treatment with MK-2206 may block the beneficial effects of galanin on these insulin-induced events. Conclusions: The results of this study suggest that phosphorylation of Akt2 mediates the beneficial effects of galanin on insulin-induced glucose uptake in the adipocytes of diabetic rats.

\section{Introduction}

Glucose homeostasis is predominantly regulated by insulin to balance glucose uptake and endogenous glucose production [1]. If glucose homeostasis is disrupted, the onset of

\section{Z. Zhang and P. Fang are co-first authors.}


Zhang et al.: Akt2 Mediates Beneficial Role of Galanin in Glucose Uptake

several diseases, including obesity, hyperglycemia and diabetes mellitus, may be triggered. In addition to insulin, recent studies found that other hormones, such as galanin, could enhance the effects of insulin on glucose uptake [2].

Galanin is a 29/30 amino-acid peptide, distributed widely throughout the nervous and digestive systems as well as other tissues [3]. As a versatile peptide, galanin can modulate many physiological functions, particularly increases in food intake, body weight and adiposity in animals [4]. Recent reports indicated that galanin might boost insulin-induced glucose transporter 4 (GLUT4) translocation and subsequent glucose uptake via activation of the Akt/PKB pathway in both fat and muscle cells $[5,6]$. The galanin receptor family comprises three members, GalR1-3 [5]. Both activated GalR1 and GalR3 may inhibit adenyl cyclase and decrease the cAMP level through Gi/o receptors, resulting in activation of Akt/PKB [5, 7]. Activated GalR2 may result in the hydrolysis of inositol phosphate and activation of atypical protein kinase $\mathrm{C}$ through the $\mathrm{Gq} / 11$ pathway to enhance intracellular $\mathrm{Ca}^{2+}$ concentration.

Akt is a main component of the insulin signaling pathway. Among the three Akt isoforms (Akt1-3), the serine/threonine kinase Akt2 is a key signaling mediator of insulin-stimulated glucose uptake into adipocytes and myocytes through the promotion of GLUT4 translocation in mice [8]. Akt2 is activated through phosphorylation at two regulatory sites, Thr308 in the activation loop and Ser473 in the hydrophobic $\mathrm{COOH}$-terminal regulatory domain [9]. Activation of Akt2 can phosphorylate numerous downstream substrates, such as the Akt substrate of $160 \mathrm{kDa}$ (AS160), forkhead box 01 (Fox01) and glycogen synthase kinase-3 (GSK-3). Akt2 and its downstream proteins are the crucial links of the insulin signaling cascade that regulate GLUT4 translocation and subsequent glucose uptake [9]. However, it is unknown whether Akt2 mediates the beneficial effect of galanin on insulin-induced glucose uptake. Accordingly, this study used MK-2206, a potent Akt inhibitor, to assess whether Akt2 mediates the facilitating impact of galanin on insulin-induced glucose uptake in diabetic rat adipocytes.

\section{Materials and Methods}

\section{Materials}

Galanin was obtained from Sigma-Aldrich Inc, USA. Insulin glargine from Ganli Pharmaceutical Co, Beijin, China. MK-2206 from Selleck Chemicals, Houston, TX, USA. 2-Deoxy-D- $\left[{ }^{3} H\right]$ glucose $\left(\left[{ }^{3} \mathrm{H}\right] 2-\mathrm{DG}\right)$ from Perkin Elmer, Boston, USA. pAS160 $16{ }^{\text {Thr642 }}$ antibody from B-Bridge International, Cupertino, CA, USA. Antibodies against vesicle-associated membrane protein 2 (VAMP2), GLUT4, pAkt2 ${ }^{\text {Thr308 }}$, pAkt2 ${ }^{\text {Ser473 }}$, pFox01 and pGSK-3 $\beta$ from Santa Cruz Biotechnology, Dallas, USA.

\section{Diabetic models and animal grouping}

Male Wistar rats $(150 \pm 10 \mathrm{~g})$ were purchased from the Animal Center of Yangzhou University and were housed for 8 weeks before experimentation in a climate-controlled environment with a high-fat diet and water ad libitum as well as a 12:12-h light-dark cycle. Then, the animals were intraperitoneally treated with 30 mg.kg-1 streptozocin [2]. After another 4 weeks, the animals with fasting blood glucose levels over $11.1 \mathrm{mmol} / \mathrm{L}$ were used as diabetic models. The animal protocol for this experiment was approved by the Animal Studies Committee of Yangzhou University.

The forty-eight model rats were randomly divided into six groups of 8 each: diabetic controls, galanin group, insulin group, insulin + MK-2206 group, insulin + galanin group, and galanin + insulin + MK-2206 group. In addition, a healthy control group was included $(\mathrm{n}=8)$. The six treatment groups were injected with galanin (1 nmol. $\mathrm{kg}^{-1}$, i.v. reference to Bu's experiment [5]), insulin glargine (2 $\mathrm{U} \cdot \mathrm{kg}^{-1}$, s.c.) and MK2206 (300 $\mu \mathrm{g} \cdot \mathrm{kg}^{-1}$, i.v. reference to Li's experiment [10]), either individually or in combination. Both control groups were injected with the vehicle. The injection was conducted once a day between 9:00-10:00 am successively for ten days. After $24 \mathrm{~h}$ of fasting after the last injection, all animals were intraperitoneally injected with $250 \mathrm{mg} \cdot \mathrm{kg}^{-1} 2$-deoxy- $\left[{ }^{3} \mathrm{H}\right]$-D-glucose $\left({ }^{3} \mathrm{H}-2 \mathrm{DG}\right)$. Thirty minutes after the injection, all rats were sacrificed by treatment with $200 \mathrm{mg} \cdot \mathrm{kg}^{-1} \mathrm{Nembutal}$. Arterial blood and the epididymal fat pad were rapidly collected and stored at $-80^{\circ} \mathrm{C}$ until further analysis. 


\section{Cellular Physiology Cell Physiol Biochem 2017;41:1777-1787 \begin{tabular}{l|l|l} 
and Biochemistry Published onlıne: March 312017 & $\begin{array}{l}\text { (c) } 2017 \text { The Author(s). Published by S. Karger AG, Basel } \\
\text { www.karger.com/cpb }\end{array}$
\end{tabular}

Fractionation of the plasma membrane and ${ }^{3} H-2 D G$ uptake measurement

The membranes of adipocytes were fractionated as described previously [2]. Briefly, the fat pads were washed, minced and homogenized in an ice-cold homogenization buffer. The homogenate was centrifuged at $13,000 \mathrm{~g}$ for $20 \mathrm{~min}$ at $4^{\circ} \mathrm{C}$. Part of the supernatant was used for measurement of ${ }^{3} \mathrm{H}-2 \mathrm{DG}$ uptake via liquid scintillation counting. The remaining supernatant was re-centrifuged at 31,000 $\mathrm{g}$ for $60 \mathrm{~min}$. The pellet from this spin was layered over a sucrose cushion and centrifuged at 75,000 $\mathrm{g}$ for $60 \mathrm{~min}$. The pellet was removed and spun for $20 \mathrm{~min}$ at 39,000 g to yield plasma membranes.

Western blot analysis

Twenty micrograms of the samples were separated on a $12 \%$ SDS-polyacrylamide gel and then transferred to polyvinylidene difluoride membranes [4]. The membranes were incubated overnight with a specific primary antibody against GLUT4, VAMP2, pAkt2 ${ }^{\text {Thr308 }}$, pAkt2 ${ }^{\text {Ser473 }}$, pAS160 ${ }^{\text {Thr462 }}$, pFoxO1 or pGSK$3 \beta$. Then, the membranes were washed and incubated with HRP-conjugated secondary antibody. The blots were visualized using an enhanced HPIAS-2000 Image Analysis System (ChampionImages, China). The densitometry values were normalized to $\beta$-actin.

Statistical analysis

The means \pm SE were analyzed by one-way ANOVA with Tukey's post hoc test and were considered significantly different at $\mathrm{P}<0.05$.

\section{Results}

Blood glucose levels

After co-administration of galanin and insulin, the blood glucose levels were reduced by $28.7 \%(\mathrm{P}<0.01)$ and $17.7 \%(\mathrm{P}<0.05)$ compared with the galanin- or insulin-treated group, respectively (Fig. 1). Pretreatments with MK-2206 significantly elevated glucose levels by $35.8 \%(\mathrm{P}<0.01)$ in the insulin + galanin $+\mathrm{MK}-2206$ group compared with the insulin + galanin group, and by $23.7 \%(\mathrm{P}<0.05)$ in the insulin+ MK-2206 group compared with the insulin group. Treatments with galanin or insulin alone significantly decreased blood glucose by 28.4\% $(\mathrm{P}<0.01)$ and $37.9 \%(\mathrm{P}<0.01)$ compared with diabetic controls, respectively. However, the blood glucose levels were reduced by only $9.6 \%(\mathrm{P}>0.05)$ in the insulin + galanin + MK-2206 group compared with the insulin+ MK-2206 group. The blood glucose levels were higher in the diabetic control group than in the healthy controls $(\mathrm{P}<0.01)$.

\section{$\left[{ }^{3} H\right] 2-D G$ uptake}

We examined glucose uptake using $\left[{ }^{3} \mathrm{H}\right] 2$ 2-DG assays in the adipocytes. After coadministration of insulin and galanin, the $\left[{ }^{3} \mathrm{H}\right] 2$-DG contents were enhanced $28.5 \%(\mathrm{P}<0.01)$ and $20.9 \%(\mathrm{P}<0.05)$ compared with galanin- or insulin-treated group, respectively (Fig. 2). Pretreatment with MK-2206 significantly reduced $\left[{ }^{3} \mathrm{H}\right] 2$ 2-DG uptake by $32.2 \%(\mathrm{P}<0.01)$ in the insulin + galanin + MK-2206 group compared with the insulin + galanin group and by $27.2 \%(\mathrm{P}<0.01)$ in the insulin $+\mathrm{MK}-2206$ group compared with the insulin group. Treatment with galanin or insulin alone significantly increased $\left[{ }^{3} \mathrm{H}\right] 2$-DG uptake by $36.9 \%(\mathrm{P}<0.05)$ and $45.5 \%(\mathrm{P}<0.01)$ compared with the diabetic controls, respectively. The content was significantly lower $(\mathrm{P}<0.01)$ in the diabetic control group than in the healthy controls $(\mathrm{P}<0.01)$. There was an insignificant difference in $\left[{ }^{3} \mathrm{H}\right] 2$ 2-DG uptake between the insulin + galanin + MK-2206 group and the insulin + MK-2206 group $(P>0.05)$.

\section{GLUT4 and VAMP2 contents in the plasma membranes}

Co-treatment with both insulin and galanin elevated the GLUT4 and VAMP2 protein levels in the plasma membranes by $38.3 \%(\mathrm{P}<0.01)$ and $29.4 \%(\mathrm{P}<0.01)$ compared with the galanin group and $25.1 \%(\mathrm{P}<0.05)$ and $23.9 \%(\mathrm{P}<0.05)$ compared with the insulin group, respectively (Fig. 3). Compared with the diabetic controls, both immunoreactivities were elevated by $39.4 \%(\mathrm{P}<0.05)$ and $56.2 \%(\mathrm{P}<0.01)$ in the galanin group and $54.1 \%(\mathrm{P}<0.01)$ 


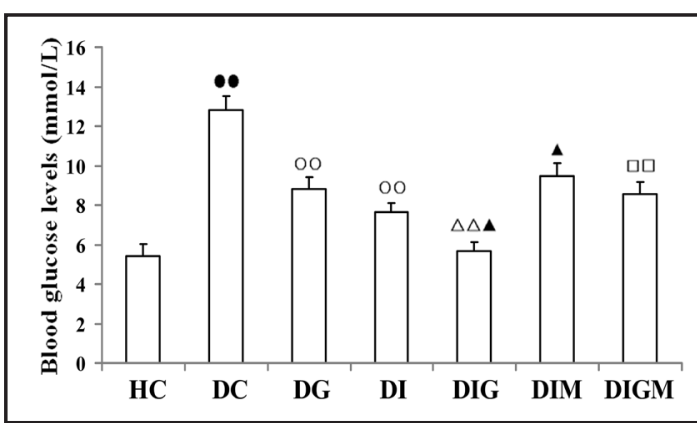

Fig. 1. Co-treatment with galanin and insulin significantly decreased blood glucose levels of type 2 diabetic rats $(n=8)$. The blood glucose levels were reduced in the insulin + galanin group (DIG) compared with either galanin group (DG) or insulin group (DI), respectively. Pretreated with MK-2206, the glucose levels were elevated in the insulin + galanin + MK-2206 group (DIGM) compared with DIG and in the insulin+ MK-2206 group (DIM) compared with DI. Treatments with galanin or insulin alone significantly decreased blood glucose compared with the diabetic controls (DC), respectively. Additionally, there was non-significant difference in blood glucose levels between DIGM and DIM. The levels were higher in DC than the healthy controls (HC). The data shown are the means \pm SEM. $\bullet \bullet P<0.01$ vs. HC; $\circ \circ \mathrm{P}$ $<0.01$ vs. DC; $\Delta \Delta \mathrm{P}<0.01$ vs. DG; $\Delta \mathrm{P}<0.05$ vs. DI; $\square \square \mathrm{P}<0.01$ vs. DIG.

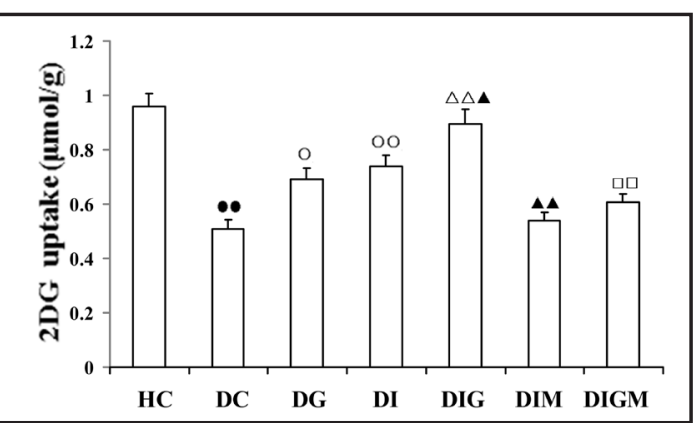

Fig. 2. Treatment with galanin increased insulin-stimulated $\left[{ }^{3} \mathrm{H}\right] 2-\mathrm{DG}$ uptake in adipocytes of type 2 diabetic rats $(n=8) .\left[{ }^{3} \mathrm{H}\right] 2 \mathrm{DG}$ uptake was increased in the insulin + galanin group (DIG) compared with either galanin group (DG) or insulin group (DI), respectively. Pretreated with MK-2206, [ $\left.{ }^{3} \mathrm{H}\right] 2-\mathrm{DG}$ uptake were reduced in the insulin + galanin + MK2206 group (DIGM) compared with DIG and in the insulin+ MK-2206 group (DIM) compared with DI. Treatments of galanin or insulin alone significantly increased $\left[{ }^{3} \mathrm{H}\right] 2-\mathrm{DG}$ uptake compared with the diabetic controls (DC). $\left[{ }^{3} \mathrm{H}\right] 2 \mathrm{DG}$ uptake was lower in DC than the healthy controls (HC). Additionally, $\left[{ }^{3} \mathrm{H}\right] 2$ DG uptake was non-significant difference between DIGM and DIM. The data shown are the means \pm SEM. $\bullet \bullet P 0.01$ vs. HC; $\circ \mathrm{P}<0.05$, O $\mathrm{P}<0.01$ vs. DC; $\Delta \Delta \mathrm{P}<0.01$ vs. DG; $\boldsymbol{\Delta} \mathrm{P}<0.05, \boldsymbol{\Delta} \boldsymbol{\Delta} \mathrm{P}<0.01$ vs. DI; $\square \square \mathrm{P}<0.01$ vs. DIG.

and $62.9 \%(\mathrm{P}<0.01)$ in the insulin group, respectively. GLUT4 and VAMP2 decreased by $30.4 \%(\mathrm{P}<0.01)$ and $32.5 \%(\mathrm{P}<0.01)$ in the insulin + galanin + MK-2206 group compared with the insulin + galanin group, respectively. Similarly, they decreased by $24.8 \%(\mathrm{P}<0.05)$ and $23.7 \%(\mathrm{P}<0.05)$ in the insulin+ MK-2206 group compared with the insulin group. The GLUT4 and VAMP2 immunoreactivities were increased in the plasma membranes by $15.8 \%$ $(\mathrm{P}>0.05)$ and $9.7 \%(\mathrm{P}>0.05)$ in the insulin + galanin + MK-2206 group compared with the insulin+ MK-2206 group, respectively. Both levels were lower in the diabetic controls $(\mathrm{P}<$ $0.01)$ than in the healthy controls $(\mathrm{P}<0.01)$.

\section{pAkt2 ${ }^{\text {Thr308 }}$ and pAkt2 ${ }^{\text {Ser473 }}$ levels in adipocytes}

To determine whether galanin affects insulin signaling, we measured the pAkt2 ${ }^{\text {Thr308 }}$ and pAkt2 ${ }^{\text {Ser473 }}$ levels in the adipocytes using Western blot assays (Fig. 4). Co-treatment with galanin and insulin significantly increased adipocyte content of pAkt2 $2^{\text {Thr308 }}$ and pAkt $2^{\mathrm{Ser} 473}$ by $25.3 \%(\mathrm{P}<0.01)$ and $19.3 \%(\mathrm{P}<0.01)$ compared with the galanin group and by $11.2 \%(\mathrm{P}<0.05)$ and $7.8 \%(\mathrm{P}<0.05)$ compared with the insulin group, respectively. After pretreatment with MK-2206, pAkt2 ${ }^{\text {Thr308 }}$ and pAkt2 $2^{\text {Ser473 }}$ levels in the insulin + galanin + MK-2206 group were reduced by $30.8 \%(\mathrm{P}<0.01)$ and $22.6 \%(\mathrm{P}<0.01)$ compared with the insulin + galanin group, respectively. They were also reduced by $29.6 \%(\mathrm{P}<0.01)$ and $22.6 \%(\mathrm{P}<0.01)$ in the insulin+ MK-2206 group compared with the insulin group, respectively. Compared with the diabetic controls, levels of both pAkt2 ${ }^{\mathrm{Thr} 308}$ and pAkt2 ${ }^{\mathrm{Ser} 473}$ were increased by $169.6 \%(\mathrm{P}<0.01)$ and $145.2 \%(\mathrm{P}<0.01)$ in the galanin group and by $202.8 \% * \mathrm{P}<0.01)$ and $171.3 \%(\mathrm{P}<0.01)$ in the insulin group, respectively. There were insignificant differences in both levels $(P>0.05)$ between the insulin + galanin + MK-2206 group and the insulin+ MK-2206 group. Again, 


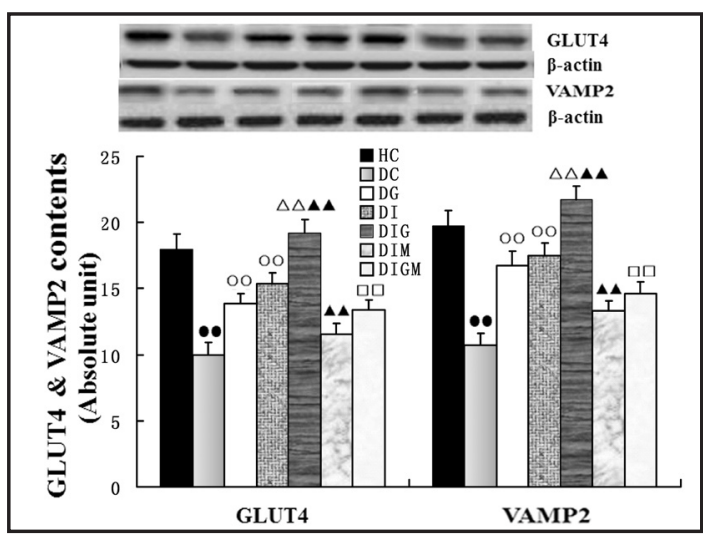

Fig. 3. Injection of galanin into the diabetic rats increased insulin-stimulated GLUT4 and VAMP2 trafficking to the plasma membranes of adipocytes $(\mathrm{n}=8)$. In the co-administration of insulin and galanin groups (DIG) the GLUT4 and VAMP2 levels in plasma membranes of adipocytes were enhanced compared with either galanin- (DG) or insulin-treated (DI) groups. The enhanced immunoreactivity in plasma membranes in DIG and DI was abolished by pretreatment of MK-2206. The immunoreactivity in galanin- or insulin-treated group was elevated in plasma membranes compared with the diabetic control group (DC). Both indexes between DIGM and DIM were non-significant difference. While both levels in plasma membranes in DC were lower than the healthy controls (HC). The data shown are the means \pm SEM. $\bullet \bullet P<0.01$ vs. HC; $\circ \circ \mathrm{P}<0.01$ vs. DC; $\Delta \Delta \mathrm{P}<$ 0.01 vs. DG; $\boldsymbol{\Delta} \boldsymbol{\Delta} \mathrm{P}<0.01$ vs. DI; $\square \square \mathrm{P}<0.01$ vs. DIG.

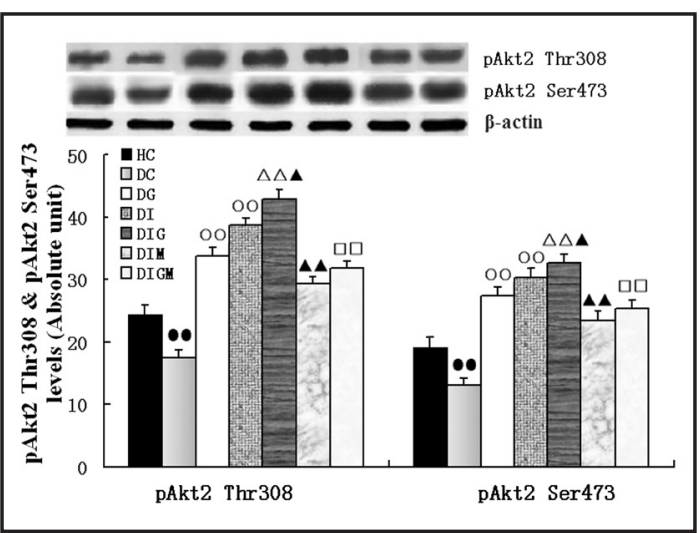

Fig. 4. Administration of galanin increased the insulin-stimulated pAkt2 ${ }^{\text {Thr308 }}$ and pAkt2 ${ }^{\text {Ser473 }}$ levels in adipocytes of diabetic rats $(n=8)$. Co-treatment with galanin and insulin significantly increased pAkt$2^{\text {Thr308 }}$ and pAkt $2^{\text {Ser473 }}$ contents in the insulin + galanin group (DIG) compared with the insulin group (DI) or the galanin group (DG). After pretreatment with MK-2206, the pAkt2 ${ }^{\text {Thr308 }}$ and pAkt2 ${ }^{\text {Ser } 473}$ levels were lower in the insulin + galanin + MK-2206 group (DIGM) than the insulin + galanin group and in the insulin + MK-2206 group (DIM) than DI. Both levels were higher in DG and DI than the diabetic controls (DC), but non-significant difference between DIGM and DIM. Both levels in DC were lower than the healthy control (HC). The data shown are the means \pm SEM. $\bullet \bullet<0.01$ vs. HC; $\circ \circ \mathrm{P}<0.01$ vs. DC; $\Delta \Delta \mathrm{P}<$ 0.01 vs. DG; $\boldsymbol{\Delta} \mathrm{P}<0.05, \boldsymbol{\Delta} \boldsymbol{\Delta} \mathrm{P}<0.01$ vs. DI; $\square \square \mathrm{P}<$ 0.01 vs. DIG.

Fig. 5. The effect of coadministration of galanin with insulin on the Akt2 mRNA expression levels in adipocytes of diabetic rats $(n=8)$. The Akt2 mRNA expression levels in the insulin + galanin group (DIG) were significantly elevated compared with the galanin group (DG) and the insulin group (DI). The levels were lower in the insulin + galanin + MK-2206 group (DIGM) than the insulin + galanin group and in the insulin + MK-2206 group (DIM) than DI. The Akt2 mRNA expression levels in DG and DI were higher

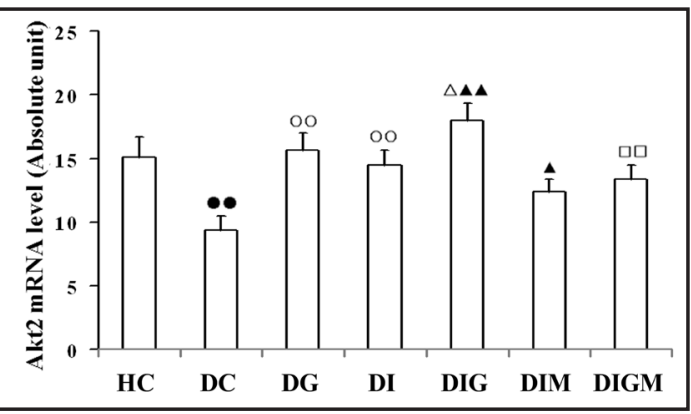
than the diabetic controls (DC), while in the DC was lower than the health controls (HC). The levels were non-significant difference between DIGM and DIM. The data shown are the means \pm SEM. $\bullet \bullet P<0.01$ vs. HC; $\mathrm{O} \circ \mathrm{P}<0.01$ vs. DC; $\Delta \mathrm{P}<0.05$ vs. DG; $\boldsymbol{\Delta} \mathrm{P}<0.05, \boldsymbol{\Delta} \boldsymbol{\Delta} \mathrm{P}<0.01$ vs. DI; $\square \square \mathrm{P}<0.01$ vs. DIG.

the levels of both were significantly lower in the diabetic controls than the healthy controls $(\mathrm{P}<0.01)$.

\section{Akt2 mRNA expression levels}

As shown in Fig. 5, co-treatment with galanin and insulin significantly elevated Akt2 mRNA expression levels by $14.9 \%(\mathrm{P}<0.05)$ and $23.9 \%(\mathrm{P}<0.01)$ compared with the galanin- or insulin-treated groups, respectively, in adipocytes. The levels were attenuated 
Fig. 6. Administration of galanin increased insulin-stimulated pAS160 $0^{\text {Thr462 }}$ levels, but reduced $\mathrm{pFo}$ $\mathrm{x} 01$ and pGSK-3 $\beta$ levels in adipocytes of the diabetic rats $(\mathrm{n}=8)$. The pAS160 ${ }^{\text {Thr462 }}$ (Fig. 5A) concentration were higher, but pFox01 (Fig. 5B) and GSK-3 $\beta$ levels (Fig. 5C) were lower in the insulin + galanin group (DIG) than either galanin group (DG) or insulin group (DI), and in DG and DI than the diabetic controls (DC), respectively. Additionally, the increase in pAS160 $0^{\text {Thrr62 }}$ contents as well as the decrease in pFox01 and pGSK-3 $\beta$ levels in the insulin + galanin group and the insulin group were abolished by pretreatment of MK-2206 in adipocytes. The three indexes were non-significant difference between both hormone + MK-2206 group (DIGM) and insulin + MK-2206 group (DIM). While the first was lower and the latter two were higher in DC than the health controls. The data shown are the means \pm SEM. $\bullet \bullet P$ $<0.01$ vs. HC; $\circ \mathrm{P}<0.05, \circ \circ \mathrm{P}<0.01$ vs. $\mathrm{DC} ; \Delta<0.05$, $\Delta \Delta \mathrm{P}<0.01$ vs. DG; $\boldsymbol{\Delta} \mathrm{P}<0.05, \boldsymbol{\Lambda} \mathbf{\Delta} \mathrm{P}<0.01$ vs. DI; $\square \square \mathrm{P}<0.01$ vs. DIG.

by $25.8 \%(\mathrm{P}<0.01)$ in the insulin + galanin + MK-2206 group compared with the insulin + galanin group and by $21.9 \%(\mathrm{P}<0.05)$ in the insulin+ MK-2206 group compared with the insulin-treated group. Compared with diabetic controls, the levels were enhanced by $67.9 \%(\mathrm{P}<0.01)$ in the galanin group and by $55.7 \%(\mathrm{P}<0.01)$ in the insulin group. There were insignificant differences in the expression levels between the insulin + galanin + MK-2206 group and the insulin + MK-2206 group. The levels were lower in the diabetic controls than the healthy controls ( $\mathrm{P}$ $<0.01$ ).

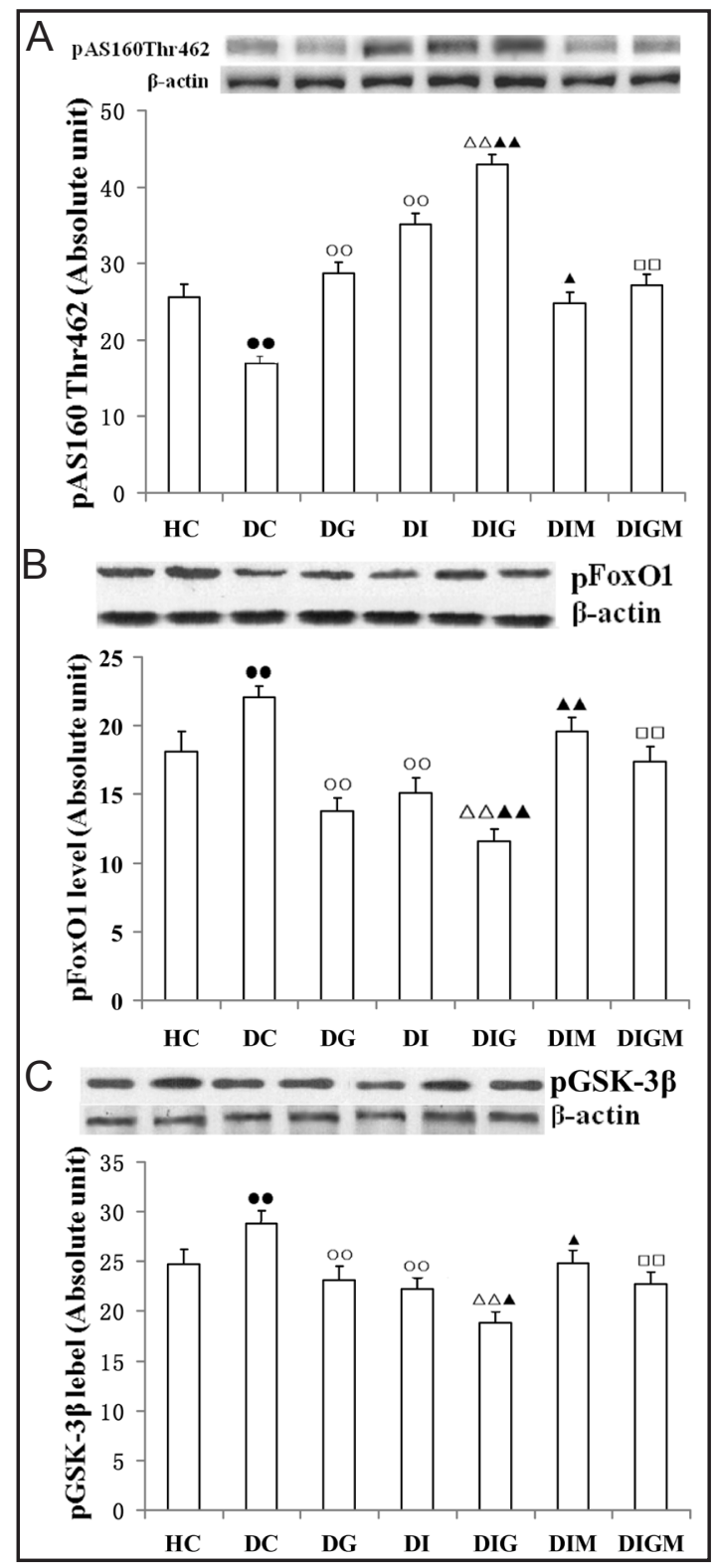

$p A S 160^{\text {Thr462, }}, p F 0 x 01$ and $p G S K-3 \beta$ levels in adipocytes

As shown in Fig. 6, the coadministration of galanin and insulin significantly elevated adipocyte pAS160 ${ }^{\text {Thr } 462}$ levels by $49.0 \%$ ( $<<0.01$ ), but attenuated adipocyte pFox01 and GSK-3 $\beta$ levels by $23.4 \%(\mathrm{P}<0.01)$ and $18.4 \%(\mathrm{P}<0.01)$, respectively, compared with the galanin group. Likewise, in adipocytes, the pAS160 ${ }^{\text {Thr462 }}$ levels increased by $22.3 \%$ ( $\mathrm{P}<$ $0.01)$, and the pFox01 and GSK-3 $\beta$ levels decreased by $21.0 \%(\mathrm{P}<0.01)$ and $13.4 \%(\mathrm{P}<$ $0.05)$, respectively, compared with the insulin group. The first index was reduced by $36.7 \%$ $(\mathrm{P}<0.01)$ and the latter two were respectively enhanced by $50.2 \%(\mathrm{P}<0.01)$ and $20.5 \%$ $(\mathrm{P}<0.01)$ in the insulin + galanin + MK-2206 group compared with the insulin + galanin group. Furthermore, the first index was reduced by $29.2 \%(\mathrm{P}<0.01)$ and the latter two were respectively enhanced by 33.9\% $(\mathrm{P}<0.05)$ and $13.9 \%(\mathrm{P}<0.05)$ in the insulin+ MK-2206 group compared with the insulin-treated group. Compared with the diabetic controls, the pAS160 ${ }^{\text {Thr462 }}$ levels were enhanced by $69.4 \%(\mathrm{P}<0.01)$ and the pFox01 and GSK-3 $\beta$ levels were reduced by $31.6 \%(\mathrm{P}<0.01)$ and $17.9 \%(\mathrm{P}<0.01)$, respectively, in the galanin group. Likewise, the first index increased $106.4 \%(\mathrm{P}<0.01)$ and the latter two decreased $33.7 \%$ 
Zhang et al.: Akt2 Mediates Beneficial Role of Galanin in Glucose Uptake

( $\mathrm{P}<0.01)$ and $22.6 \%(\mathrm{P}<0.01)$, respectively, in the insulin group compared to the diabetic controls. Differences in the three indexes were not significant between the insulin + galanin + MK-2206 group and the insulin+ MK-2206 group; however, the first one was lower and the last two were higher in the diabetic controls compared to the healthy controls $(\mathrm{P}<0.01)$.

\section{Discussion}

It is well known that adipose tissue serves not only as a fat depot but also as an important organization for insulin-stimulating glucose uptake because GLUT4 expression is selectively down-regulated in adipose tissue, but not in skeletal muscle, during the progression of insulin-resistant and diabetes [11]. Defects in insulin-stimulating glucose uptake in adipose tissue may trigger the onset of type 2 diabetes mellitus. In this study, we evaluated the effect of galanin on insulin-induced glucose uptake in the adipocytes of diabetic animals from multiple aspects.

First, we assessed the impact of galanin on insulin-induced GLUT4 and VAMP2 distribution along with blood glucose and $\left[{ }^{3} \mathrm{H}\right]$ 2-DG uptake levels. GLUT4 plays a key role in facilitating glucose uptake after insulin stimulation in adipose and muscle tissues. Under basal conditions, most of GLUT4 is retained in intracellular storage compartments termed GLUT4 storage vesicles [4]. After insulin stimulation, GLUT4 is quickly exocytosed from these compartments to plasma membranes, leading to a net accumulation of GLUT4 on the cell surface that is followed by an increase in glucose uptake [2]. In addition, VAMP2 is necessary for trafficking GLUT4 vesicles to dock and fuse with the target membrane compartment, which is an important step in insulin-regulating GLUT4 translocation [12]. An injection of VAMP2 neurotoxin or overexpression of dominant-interfering VAMP2 peptides inhibited GLUT4 translocation. Thus, insulin-dependent increases in GLUT4 and VAMP2 translocation to plasma membranes is closely associated with expedited sugar influx into cells [13]. In addition to insulin, the administration of galanin may also catalyze GLUT4 translocation. Animals with galanin metabolic disorder were found to easily develop type 2 diabetes mellitus [14]. Galanin knockout mice showed that insulin sensitivity and insulinindependent glucose elimination were significantly decreased during a glucose tolerance test [15]. Contrarily, in homozygous galanin transgenic mice insulin sensitivity and glucose clearance were increased [16]. Our previous studies found that treatment with a galanin antagonist, M35, decreased GLUT4 translocation and glucose uptake in adipocytes, i.e., endogenous galanin can elevate GLUT4 translocation and glucose uptake in diabetic rats [2]. Furthermore, Bu et al. found that galanin may benefit insulin-induced GLUT4 translocation and subsequent glucose uptake [5]. In line with these studies, the present results revealed that co-administration of galanin and insulin compared to treatment with either hormone individually significantly increased $\left[{ }^{3} \mathrm{H}\right] 2-\mathrm{DG}$ influx and GLUT4 and VAMP2 translocation, but reduced blood glucose levels, further manifesting that injection of galanin can facilitate insulin-stimulating glucose uptake in the adipocytes of diabetic animals.

Next, we observed the effect of galanin on insulin-induced phosphorylation of Akt, which is an important loop of the insulin cascade. The canonical pathway that triggers GLUT4 translocation is composed of phosphatidylinositol-3 kinase, Akt, etc. [9]. Galanin can activate the Akt signaling pathway, too [7]. Thus, both signaling pathways of galanin and insulin involve the same signaling protein, Akt, which becomes the convergence point and intersection of both signaling pathways that trigger GLUT4 traffic.

Despite possessing close sequence homology, Akt1-3 each manifest distinct distributions and functions, which were revealed by knockout analysis [17]. Akt1 is ubiquitously expressed for the essential regulation of normal growth, and Akt3 is most abundantly expressed in the brain, correlating with the development of normal brain size. Akt 2 is predominantly expressed in brown fat and the heart and is specifically involved in the adjustment of glucose homeostasis [17]. Though multiple isoforms of Akt are expressed in adipocytes, only Akt2 is important for insulin-dependent GLUT4 translocation and glucose uptake [18, 19]. Akt2 knockout mice, 


\section{Cellular Physiology Cell Physiol Biochem 2017;41:1777-1787 \\ \begin{tabular}{ll|l} 
DOI: 10.1159/000471870 & and Biochemistry 2017 The Author(s). Published by S. Karger AG, Basel \\
Published online: March 312017 & $\begin{array}{l}\text { www.karger.com/cpb } \\
\text { and }\end{array}$
\end{tabular}}

Zhang et al.: Akt2 Mediates Beneficial Role of Galanin in Glucose Uptake

not Akt1- and Akt3-null mice, were characterized by insulin resistance, accompanied with hyperglycemia, hyperinsulinemia and defects in insulin-dependent glucose uptake $[19,20$, 21], suggesting that Akt2 is essential for insulin-dependent glucose uptake [6]. In addition, Dr. Xie et al found that pAkt2 expression in the peri-infarct area and ischemic core of brains $24 \mathrm{~h}$ after stroke was higher than self-controls before experimental onset in ischemic nude rats, implicating that elevated phosphorylation of Akt2 endured overnight [22]. In this study, we found that not only Akt2 mRNA but also pAkt2 ${ }^{\text {Thr308 }}$ and pAkt2 ${ }^{\text {Ser473 }}$ expression levels were up-regulated in the galanin and insulin groups after overnight fasting and that these levels were even higher in the insulin + galanin group compared to the galanin- or insulintreated groups. These findings suggest that interaction and interplay between both signaling cascades might enhance Akt2 expression and amplify pAkt2 intensity, and as a consequence, GLUT4 translocation and glucose uptake were elevated in the adipocytes of diabetic rats.

Furthermore, we assessed the effect of galanin on the phosphorylation of Akt2downstream targets, AS160, Fox01 and GSK-3, which reflected the efficacy of pAkt2 action in the regulation of glucose uptake. First, phosphorylation of AS160 was recently identified as an important link between insulin-induced activation of Akt2 and increases in GLUT4 translocation [19]. Attenuation of insulin-stimulated phosphorylation of AS160 was accompanied by a reduction in insulin sensitivity and glucose disposal [23]. In Akt2null mice, insulin-stimulated phosphorylation of AS160 was almost completely eliminated [24]. Although AS160 can be phosphorylated at several other sites by Akt, phosphorylation at Thr642 is especially important for AS160 to regulate GLUT4 translocation [25]. Second, forkhead box $\mathrm{O}$ is the $\mathrm{O}$ type subfamily of the forkhead transcription factor superfamily, which mainly includes FoX01, FoX03, FoX04 and FoX06 [26]. In mammals, FoxO1 is the major isoform and downstream effecter of insulin signaling [27]. As Fox01 is inactive in its basal form, insulin via pAkt triggers Fox01 phosphorylation and translocation to negatively regulate metabolism. Overexpression of Fox01 via microinjection of adenovirus resulted in hyperphagia, weight gain and glucose intolerance $[27,28]$. Conversely, injection of a Fox01antisense oligonucleotide or ablation of FoxO1 in Pomc neurons decreased food intake and the body weight of animals [29]. Third, GSK-3 is a serine-directed kinase implicated in insulin action and adipogenesis. GSK-3 expression was upregulated in the adipose tissue and skeletal muscle of animals with insulin-resistance and in patients with obesity and type 2 diabetic [30]. Administration of insulin could phosphorylate and inactivate GSK-3, leading to an increase in glycogen synthase. Administration of GSK-3 inhibitors improved insulin action and glucose metabolism in humans and rodents [30]. Constitutive activation of GSK-3 in vitro or overexpression of GSK-3 $\beta$ resulted in insulin resistance. In homozygous knock-in mice, inactivation of GSK-3 $\beta$ was a major route through which insulin activated glycogen synthase [31]. Consistent with these studies, the results of this study showed that the injection of insulin enhanced the phosphorylation of Akt2 at Thr308/Ser473 and the subsequent phosphorylation of AS160 but inhibited the phosphorylation of Fox01 and GSK$3 \beta$. Co-treatment with galanin and insulin further boosted these insulin-mediated events, which were followed by enhanced GLUT4 translocation and glucose uptake.

Last, most of the Akt inhibitors may be used only in vitro, while MK-2206, which is a potent non-ATP competitive Akt inhibitor, may be used both in vitro and in vivo in animal and clinical tests [32]. Dr. Hirai and colleagues found that MK-2206 inhibitors combined with other anti-tumor agents had more potent inhibitive impacts on tumor growth in vivo than every agent alone in monotherapy conditions, suggesting that Akt inhibitors may cooperate with existing anti-cancer therapeutics to augment their efficacy. In this study, the beneficial effects of galanin on insulin-induced glucose uptake, including GLUT4 and VAMP2 translocation and phosphorylation of Akt2, AS160, FoxO1 and GSK-3 $\beta$, were blocked by pretreatment with MK-2206. In addition, galanin was unable to potentiate the above insulininduced events after injection with MK-2206, suggesting that phosphorylation of Akt2 was essential for galanin to promote insulin-stimulated glucose uptake. Namely, phosphorylation of Akt2 mediates the beneficial effect of galanin on insulin-induced glucose uptake in the adipocytes of diabetic rats. Moreover, Dr. Hirai and colleagues explored the time-response 


\section{Cellular Physiology Cell Physiol Biochem 2017;41:1777-1787 \begin{tabular}{ll|l} 
DOI: 10.1159/000471870 & $\begin{array}{l}\text { O 2017 The Author(s). Published by S. Karger AG, Basel } \\
\text { www.karger.com/cpb }\end{array}$
\end{tabular}

curve of oral administration of MK-2206 at $120 \mathrm{mg} / \mathrm{kg} 3$ times a week in xenograft tumor models of mice [32]. They found that although MK-2206 could significantly inhibit tumor growth on the ninth day after administration, the agent yielded a greater inhibition of tumor growth on the fourteenth and sixteenth day than on the ninth day. In the current experiment, after treatment with MK-2206 for ten days, the beneficial effects of galanin on insulin-induced events were obviously blocked. Undoubtedly, if treatment with the agent proceeded for a longer duration than ten days, we likely would have observed better efficacy and more significant biomarker responses than in this slow experiment, which is one of the deficiencies of the present study.

In short, this study provides compelling evidence that activation of the Akt2 pathway was necessary to promote the effects of galanin on insulin-stimulated GLUT4 and VAMP2 translocation to the plasma membranes and subsequent glucose uptake in the adipocytes of diabetic animals. Moreover, galanin injection increased the insulin-stimulated phosphorylation of Akt2 and AS160 but reduced the phosphorylation of Fox01 and GSK-3 $\beta$ concomitant with elevated glucose uptake, which became refractory after exposure to MK2206 in adipocytes. These findings implicate Akt2 phosphorylation as the key mediator of galanin in enhancing insulin-induced glucose uptake in the adipocytes of diabetic animals.

\section{Abbreviations}

GLUT4 (glucose transporter 4); AS160 (Akt substrate of $160 \mathrm{kDa}$ ); Fox01 (forkhead box 01); GSK-3 (glycogen synthase kinase-3); [ $\left.{ }^{3} \mathrm{H}\right] 2-\mathrm{DG}$ (2-Deoxy-D-[ $\left.{ }^{3} \mathrm{H}\right]$ glucose); VAMP2 (vesicle-associated membrane protein 2).

\section{Acknowledgements}

This work was supported by Open Projects of Zoonosis Key Laboratory of Jiangsu Province (R1504), and National Natural Scientific Fund of China (81673736), and National Health and Family Planning Commission of China (W201309).

\section{Disclosure Statement}

The authors have no conflict of interest.

\section{References}

1 Yea K, Kim J, Yoon JH, Kwon T, Kim JH, Lee BD, Lee HJ, Lee SJ, Kim JI, Lee TG, Baek MC, Park HS, Park KS, Ohba M, Suh PG, Ryu SH: Lysophosphatidylcholine activates adipocyte glucose uptake and lowers blood glucoselevels in murine models of diabetes. J Biol Chem 2009;284:33833-33840.

-2 Zhang Z, Sheng S, Guo L, Li G, Zhang L, Zhang L, Shi, M Bo P, Zhu Y: Intracerebroventricular administration of galanin antagonist sustains insulin resistance in adipocytes of type 2 diabetic trained rats. Mol Cell Endocrinol 2012;361:213-218.

-3 Fang P, Yu M, Shi M, Zhang Z, Sui Y, Guo L, Bo P: Galanin peptide family as a modulating target for contribution to metabolic syndrome. Gen Comp Endocrinol 2012;179:115-120.

4 He B, Shi M, Zhang L, Guo L, Zhang L, Shao H, Li J, Fang P, Ma Y, Shi Q Sui Y: Beneficial effect of galanin on insulin sensitivity in muscle of type 2 diabetic rats. Physio Behav 2011;103:284-289.

5 Bu L, Yao Q Liu Z, Tang W, Zou J, Qu S: Combined galanin with insulin improves insulin sensitivity of diabetic rat muscles. J Endocrinol 2014;221:157-165.

6 Ng Y, Ramm G, Lopez JA, James DE: Rapid activation of Akt2 is sufficient to stimulate GLUT4 translocation in 3T3-L1 adipocytes. Cell Metabolism 2008;7:348-356. 


\section{Cellular Physiology Cell Physiol Biochem 2017;41:1777-1787 \begin{tabular}{ll|l} 
DOI: 10.1159/000471870 & C 2017 The Author(s). Published by S. Karger AG, Basel \\
www.karger.com/cpb
\end{tabular}

Zhang et al.: Akt2 Mediates Beneficial Role of Galanin in Glucose Uptake

7 Thimmaiah KN, Easton JB, Germain GS, Morton CL, Kamath S, Buolamwini JK, Houghton PJ: Identification of N10-substituted phenoxazines as potent and specific inhibitors of Akt signaling. J Biol Chem 2005;280:31924-31925.

8 Zhou QL, Park JG, Jiang ZY, Holik JJ, Mitra P, Semiz S, Guilherme A, Powelka AM, Tang X, Virbasius J, Czech MP: Analysis of insulin signaling by RNAi-based gene silencing. Biochem Soc Trans 2004;32:817-821.

-9 Feng XT, Wang TZ, Chen Y, Liu JB, Liu Y, Wang WJ: Pollen Typhae total flavone improves insulininduced glucose uptake through the $\beta$-arrestin-2-mediated signaling in C2C12 myotubes. Int J Mol Med 2012;30:914-922.

-10 Li Q Shi M, Li B: Anandamide enhances expression of heat shock protein 72 to protect against ischemiareperfusion injury in rat heart. J Physiol Sci 2013;63:47-53.

11 Guo LL, Shi MY, Zhang L, Li G, Zhang L, Shao H, Fang P, Ma Y, Li J, Shi Q, Sui Y: Galanin antagonist increases insulin resistance by reducing glucose transporter 4 effect in adipocytes of rats. Gen Comp Endocrinol 2011;173:159-163.

12 Williams D, Pessin JE: Mapping of R-SNARE function at distinct intracellular GLUT4 trafficking steps in adipocytes. J Cell Biol 2008;180:375-387.

13 Holman GD, Sandoval IV: Moving the insulin-regulated glucose transporter GLUT4 into and out of storag. Trends Cell Biol 2001;11:173-179.

14 Legakis IN: The role of galanin in metabolic disorders leading to type 2 diabetes mellitus. Drug News Perspect 2005;18:173-177.

15 Ahrén B, Pacini G, Wynick D, Wierup N, Sundler F: Loss-of-function mutation of the galanin gene is associated with perturbed islet function inmice. Endocrinology 2004;145:3190-196.

-16 Poritsanos NJ, Mizuno TM, Lautatzis ME, Vrontakis M: Chronic increase of circulating galanin levels induces obesity and marked alterations in lipid metabolism similar to metabolic syndrome. Int J Obes 2009;33:1381-1389.

17 Sakamoto K, Arnolds DE, Fujii N, Kramer HF, Hirshman MF, Goodyear LJ: Role of Akt2 in contractionstimulated cell signaling and glucose uptake in skeletal muscle. Am J Physiol Endocrinol Metab 2006;291:E1031-E1037.

18 McCurdy CE, Cartee GD: Akt2 is essential for the full effect of calorie restriction on insulin-stimulated glucose uptake in skeletal muscle. Diabetes 2005;54:1349-1356.

19 Sharma N, Arias EB, Sajan MP, MacKrell JG, Bhat AD, Farese RV, Cartee GD: Insulin resistance for glucose uptake and Akt2 phosphorylation in the soleus, but not epitrochlearis, muscles of old vs. adult rats. J Appl Physiol (1985) 2010;108:1631-1640.

20 Cho H, Mu J, Kim JK, Thorvaldsen JL, Chu Q, Crenshaw EB III, Kaestner KH, Bartolomei MS, Shulman GI, Birnbaum MJ: Insulin resistance and a diabetes mellitus-like syndrome in mice lacking the protein kinase Akt2 (PKB beta). Science 2001;292:1728-1731.

-21 Jiang ZY, Zhou QL, Colemanm KA, Chouinard M, Boese Q, Czech MP: Insulin signaling through Akt/ protein kinase B analyzed by small interfering RNA-mediatedgene silencing. Proc Natl Acad Sci USA 2003;100:7569-7574.

22 Xie R, Wang P, Ji X, Zhao H. Ischemic post-conditioning facilitates brain recovery after stroke by promoting Akt/mTOR activity innude rats. J Neurochem 2013;127:723-732.

-23 Kramer HF, Witczak CA, Fujii N, Jessen N, Taylor EB, Arnolds DR, Sakamoto K, Hirshman MF, Goodyear LJ: Distinct signals regulate AS160 phosphorylation in response to insulin, AICAR, and contraction in mouse skeletal muscle. Diabetes 2006;55:2067-2076.

24 Thyfault JP, Cree MG, Zheng D, Zwetsloot JJ, Tapscott EB, Koves TR, Ilkayeva O, Wolfe RR, Muoio DM, Dohm GL: Contraction of insulin-resistant muscle normalizes insulin action in association with increased mitochondrial activity and fatty acid catabolism. Am J Physiol Cell Physio 2007;292:C729-C739.

25 Sano H, Kane S, Sano E, Miinea CP, Asara JM, Lane WS, Garner CW, Lienhard GE: Insulin-stimulated phosphorylation of a Rab GTPase-activating protein regulates GLUT4 translocation. J Biol Chem 2003;278:14599-14602.

26 Xie Q, Chen J, Yuan Z: Post-translational regulation of FOXO. Acta Biochim Biophys Sin (Shanghai) 2012;44:897-901.

27 Kim HJ, Kobayashi M, Sasaki T, Kikuchi O, Amano K, Kitazumi T, Lee YS, Yokota-Hashimoto H, Susanti VY, Kitamura YI, Nakae J, Kitamura T: Overexpression of FoxO1 in the hypothalamus and pancreas causes obesity and glucoseintolerance. Endocrinology 2012;153:659-671. 


\section{Cellular Physiology Cell Physiol Biochem 2017;41:1777-1787 \begin{tabular}{l|l} 
DOI: 10.1159/000471870 & $\begin{array}{l}\text { O 2017 The Author(s). Published by S. Karger AG, Basel } \\
\text { www.karger.com/cpb }\end{array}$ \\
\hline
\end{tabular} \\ Zhang et al.: Akt2 Mediates Beneficial Role of Galanin in Glucose Uptake}

28 Sasaki T, Kitamura T: Roles of Fox01 and Sirt1 in the central regulation of food intake. Endocr J 2010;57:939-946.

-29 Ropelle ER, Pauli JR, Prada P, Cintra DE, Rocha GZ, Moraes JC, Frederico MJ, da Luz G, Pinho RA, Carvalheira JB, Velloso LA, Saad MA, De Souza CT: Inhibition of hypothalamic Foxo1 expression reduced food intake in diet-induced obesity rats. J Physiol 2009;587:2341-2351.

-30 Bouskila M, Hirshman MF, Jensen J, Goodyear LJ, Sakamoto K: Insulin promotes glycogen synthesis in the absence of GSK3 phosphorylation in skeletal muscle. Am J Physiol Endocrinol Metab 2008;294:E28-E35.

-31 McManus EJ, Sakamoto K, Armit LJ, Ronaldson L, Shpiro N, Marquez R, Alessi DR: Role that phosphorylation of GSK3 plays in insulin and Wnt signalling defined by knockinanalysis. EMBO J 2005;24:1571-1583.

32 Hirai H, Sootome H, Nakatsuru Y, Miyama K, Taguchi S, Tsujioka K, Ueno Y, Hatch H, Majumder PK, Pan BS, Kotani H: MK-2206, an allosteric Akt inhibitor, enhances antitumor efficacy by standard chemotherapeutic agentsor molecular targeted drugs in vitro and in vivo. Mol Cancer Ther 2010;9:1956-1967. 